\title{
Association of Hypertension With Erectile Function in Chronic Peripheral Arterial Insufficiency Patients
}

\author{
Luis Cesar Fava Spessoto ${ }^{\mathrm{a}, \mathrm{d}}$, Fernando Nestor Facio Jr${ }^{\mathrm{a}}$, Jose Germano Ferraz de Arruda ${ }^{\mathrm{a}}$, \\ Pedro Francisco F. Arruda a, Marcio Gattia, Thiago Silveira Antoniassia, \\ Maria Fernanda Warick Facio ${ }^{\mathrm{b}}$, Jose Maria Pereira de Godoy ${ }^{\mathrm{c}}$
}

\begin{abstract}
Background: Risk factors may influence the improvement or worsening of erectile dysfunction (ED). The aim of the current study was to evaluate the effect of systemic hypertension on ED in patients with peripheral arterial disease.

Methods: The effect of hypertension on ED was assessed in 125 consecutive patients in a cross-sectional quantitative study. The ages of the patients ranged from 19 to 88 years old (mean: $59.82 \pm 10.48$ years). The only exclusion criterion was the amputation of one or both legs. The ankle-arm index was assessed and the international index of ED questionnaire was applied to all participants in the study.

Results: Of the 125 patients, 22 (17.6\%) had mild (grade 1), 50 (40.0\%) had moderate (grade 2) and 53 (42.4\%) had severe (grade 3) ED. Hypertensive patients have more ED, with ED in hypertensive patients being associated to chronic arterial disease. However, in comparison with normotensive patients, hypertension exerts an immediate protective effect on erectile function.
\end{abstract}

Conclusions: In conclusion, although erectile function is initially protected by systemic arterial hypertension in patients with chronic arterial disease, both chronic arterial disease and ED deteriorate over the long term in hypertensive patients.

Keywords: Erectile dysfunction; Hypertension; Chronic arterial disease

\section{Introduction}

Erectile dysfunction (ED) is a common condition; it affects 18

Manuscript accepted for publication June 06, 2016

a Department of Urology, Medicine School of Sao Jose do Rio Preto (FAMERP), SP, Brazil

${ }^{\mathrm{b}}$ Ceres College (FACERES), Sao Jose do Rio Preto, SP, Brazil

'Department of Cardiology and Cardiovascular Surgery, Medicine School of Sao Jose do Rio Preto (FAMERP), SP, Brazil

${ }^{d}$ Corresponding Author: Luis Cesar Fava Spessoto, Av. Faria Lima 5416, 15090-000, Sao Jose do Rio Preto, SP, Brazil. Email: 1cspessoto@gmail.com

doi: http://dx.doi.org/10.14740/jocmr2518w million men and their sexual partners in the United States and is generally related to changes in blood flow to the penis [1]. Decreased arterial elasticity, high resting heart rate and metabolic syndrome are important cardiovascular risk markers associating arteriosclerosis, a disease associated to, among other things, ED [2].

A vascular etiology, with disease of the small vessels (microcirculation) as in diabetes mellitus and of the macrocirculation, is identified in up to $60 \%$ of patients with ED [3]. The most important risk factors for the development of advanced chronic arterial disease (CAD) include diabetes, smoking, hypertension, dyslipidemia, age over 65 years, obesity and an ankle-brachial index $(\mathrm{ABI})<0.7$ [4-6].

Another symptom of CAD is ED, which is characterized by a persistent inability of a man to achieve or maintain an erection sufficient for satisfactory sexual intercourse [7]. Research correlating $\mathrm{CAD}$ and $\mathrm{ED}$ using the international index of erectile function (IIEF) and the ABI found that ED is an independent predictive factor of $\mathrm{CAD}$; there is a positive correlation between the two diseases [8]. Another study reports that high blood pressure in patients with early stage CAD exerts a protective effect on ED [9]. The aim of this study was to assess the effect of systemic hypertension on ED in patients with CAD.

\section{Methods}

The effect of hypertension on ED was assessed in 125 consecutive patients in a cross-sectional quantitative study. Patients with ED, treated in the Vascular Surgery and Urology Outpatient Clinic of the Medicine School in Sao Jose do Rio Preto, Sao Paulo, Brazil, were evaluated in the period from March to October 2011. Patients' ages ranged from 19 to 88 years (mean: $59.82 \pm 10.48$ years). The only exclusion criterion was the amputation of one or both legs.

A general medical history was taken and the international index of erectile dysfunction (IIED) questionnaire was applied to classify the degree of ED as mild, moderate or severe [10]. When the score of the index is between 17 and 24, the ED is mild (grade 1), between 10 and 16, it is moderate (grade 2) and when the score is less than 10, it is severe (grade 3).

Additionally, the ankle-arm index was assessed; CAD is defined as a ratio of less than 0.9 .

The data were analyzed using descriptive (mean, standard deviation, median, minimum and maximum) and inferential 
Table 1. The Degree of Erectile Dysfunction in Normotensive and Hypertensive Patients

\begin{tabular}{llll}
$\begin{array}{l}\text { Degree of erectile } \\
\text { dysfunction }\end{array}$ & Hypertensive & Normotensive & $\begin{array}{l}\text { Total, } \\
\mathbf{n}(\mathbf{\%})\end{array}$ \\
\hline I & 16 & 6 & $22(17.6)$ \\
II & 27 & 23 & $50(40.0)$ \\
III & 36 & 17 & $53(42.4)$ \\
\hline
\end{tabular}

statistics. The unpaired $t$-test, Kruskal-Wallis test, odds ratio, Bonferroni correction and ordinal logistic regression were used with an $\alpha$ error of $5 \%$ (P-value $<0.05)$ being considered significant. This study was approved by the Research Ethics Committee of the Medicine School in Sao Jose do Rio Preto (\#081/2011) and all patients gave their written consent.

\section{Results}

One hundred and twenty-five patients were enrolled in this study, 22 (17.6\%) had mild (grade 1), 50 (40.0\%) had moderate (grade 2) and $53(42.4 \%$ ) had severe (grade 3 ) ED (Table 1).

On comparing the degree of ED in hypertensive and normotensive patients with CAD, the mean $\mathrm{ABI}$ is lower in hypertensive patients with grade I and II ED (unpaired $t$-test) but there is no significant difference in grade III ED (Table 2).

Considering hypertensive patients with CAD $(n=65)$ and normotensive patients with CAD $(\mathrm{n}=60)$, hypertensive patients had significantly more grade III ED than the normotensive patients $(\mathrm{P}=0.015)$.

Simple ordinal logistic regression of the degree of ED, ABI greater than or less than 0.9 and hypertension demonstrate a tendency $(\mathrm{P}<0.0005)$ of an increasing risk in the degree of ED following the order: hypertension $+\mathrm{ABI} \geq 0.9$, hypertension $+\mathrm{ABI}<0.9$ and normotension $+\mathrm{ABI}<0.9$ (Table 3). In general, patients with hypertension have a greater chance of ED than normotensive individuals. However, in patients with chronic arterial insufficiency, normotensive patients have a seven-fold higher chance of ED than hypertensive patients.

\section{Discussion}

This study correlates ED, hypertension and CAD. All hypertensive patients with ED, independent of the degree of the dysfunction, have $\mathrm{CAD}$ and high blood pressure increases the chance of having ED. However, normotensive patients with
CAD have a seven-time higher chance of ED than hypertensive patients. This correlation has not been well evaluated in the literature; an initial assessment of publications showed the protective effect of CAD on erectile function. Thus, a need arose to investigate the correlation that exists between these three variables.

What draws the attention is that high blood pressure is one of the risk factors of both CAD, due to arteriosclerosis, and ED. On the other hand, it is a protective factor for erectile function in patients with $\mathrm{CAD}$, thereby causing a therapeutic conflict.

The vascular surgeon uses the blood flow and systemic blood pressure as the main parameters to evaluate peripheral artery disease. In the case of changes in the blood flow, as in the case of the CAD, where a mechanical reduction in the flow occurs with a reduction in the vessel lumen, there is a reduction of distal systolic blood pressure to the limb. Improvement in the systolic pressure in CAD is an essential objective of treatment of severe cases of the disease. In this case, bypass surgery and endovascular procedures are used to increase the systolic pressure which automatically increases the ankle-arm index. Thus, higher systolic pressures allow better perfusion of the limb.

The current study demonstrates that in general hypertension worsens both CAD and increases the chance of ED. The benefit of hypertension in ED in patients with peripheral artery disease is improved erectile function; however, this is also one of the main aggravating factors of the disease over the long term and is one of the major causes of death. Thus, the need to control hypertension is not questioned.

In relation to the clinical treatment of peripheral arterial disease, the use of vasodilators, when possible, is a clinical option. In urology, the treatment of ED involves vasodilatory drugs such as sidenafil, vardanafil and other drugs to improve blood flow and sexual performance. The surgical alternative is a penile prosthesis.

Regarding the practical aspects, this study acts as a warning for hypertensive patients with ED who arrive at the urologist's office; there is a need to assess peripheral blood disease.

While not lethal, the impact of ED on the life of the individual is of considerable importance, economically damaging with costs that include medical evaluations, drug therapy and diagnostic examinations, interfering negatively in the patients work, and affecting the self-esteem, family relationships and quality of life $[11,12]$.

This study identifies a $75 \%$ increase in risk for peripheral artery disease in patients with ED [13]. Another assessment recommended in the clinical evaluation of patients with ED is the ankle-arm index as this is an opportunity to identify associated comorbidities such as, for example, hypertension and peripheral artery disease [14].

Table 2. Mean Ankle-Arm Ratios in Grade 1, 2 and 3 Erectile Dysfunction in Normotensive and Hypertensive Patients

\begin{tabular}{lllll}
\hline Degree of erectile dysfunction & Hypertension & Normotension & $\mathbf{P}$ & $\mathbf{9 5 \%}$ confidence interval \\
\hline 1 & 0.716667 & 0.976875 & 0.0156 & $0.07786-0.442557$ \\
\hline 2 & 0.752174 & 0.866923 & 0.0223 & $0.017087-0.212411$ \\
3 & 0.718056 & 0.824706 & 0.0838 & $-0.012566-0.225866$ \\
\hline
\end{tabular}


Table 3. Results of Trend in Increasing Odds Ratio With Categories Sorted in the Model for Erectile Dysfunction

\begin{tabular}{lllllll}
\hline Predictor & Coefficient & SE coefficient & Z & P & Odds ratio & 95\% CI \\
\hline H-ABI $\geq 0.9$ & 0.51614 & 0.833204 & 0.62 & 0.536 & 1.68 & $0.33-8.58$ \\
H-ABI $<0.9$ & 1.41970 & 0.514202 & 2.76 & 0.006 & 4.14 & $1.51-11.33$ \\
N-ABI $<0.9$ & 1.95550 & 0.441215 & 4.43 & 0.000 & 7.07 & $2.98-16.78$ \\
\hline
\end{tabular}

$\mathrm{H}$ : hypertension; N: normotension; SE: standard error; 95\% Cl: 95\% confidence interval.

Hypertension is one of the main risk factors of arteriosclerosis. Changes in blood pressures correlate with this perfusion as minimum pressures are required for functional effectiveness. In ED, increases in pressure initially allow a higher flow and perfusion; however, in the long term this is harmful, compounding the arteriosclerosis and arterial occlusion.

\section{Conclusions}

Hypertension increases the chance of ED, but in patients with peripheral artery disease, it exerts a protective effect. However, in the long term, hypertension is an aggravating factor for both diseases.

\section{Conflicts of Interest}

The authors state that they have no conflicts of interest to declare concerning the present work.

\section{References}

1. Williams JK, Andersson KE, Christ G. Animal models of erectile dysfunction (ED): potential utility of non-human primates as a model of atherosclerosis-induced vascular ED. Int J Impot Res. 2012;24(3):91-100.

2. Pohjantahti-Maaroos H, Palomaki A, Hartikainen J. Erectile dysfunction, physical activity and metabolic syndrome: differences in markers of atherosclerosis. BMC Cardiovasc Disord. 2011;11:36.

3. Odriozola AA, Quintanilla MG, Arias JG, Tamayo AL, Gonzalez GI. [Vascular erectile dysfunction]. Arch Esp Urol. 2010;63(8):611-620.

4. Norgren L, Hiatt WR, Dormandy JA, Nehler MR, Harris KA, Fowkes FG, Bell K, et al. Inter-Society Consensus for the Management of Peripheral Arterial Disease (TASC II). Eur J Vasc Endovasc Surg. 2007;3(Suppl 1):S1-75.

5. Sichel L, Chiavetta A, Soma PF, Failla G, Basile A, La Greca G, Scalisi A. [Critical ischemia of the diabetic patient]. Minerva Chir. 2001;56(3):265-271.

6. Lijmer JG, Hunink MG, van den Dungen JJ, Loonstra J, Smit AJ. ROC analysis of noninvasive tests for peripheral arterial disease. Ultrasound Med Biol. 1996;22(4):391398.

7. NIH Consensus Conference. Impotence. NIH Consensus Development Panel on Impotence. JAMA. 1993;270(1):83-90.

8. Polonsky TS, Taillon LA, Sheth H, Min JK, Archer SL, Ward RP. The association between erectile dysfunction and peripheral arterial disease as determined by screening ankle-brachial index testing. Atherosclerosis. 2009;207(2):440-444.

9. Spessoto LC, Cordeiro JA, de Godoy JM. Effect of systemic arterial pressure on erectile dysfunction in the initial stages of chronic arterial insufficiency. BJU Int. 2010;106(11):1723-1725.

10. Rosen RC, Riley A, Wagner G, Osterloh IH, Kirkpatrick $\mathrm{J}$, Mishra A. The international index of erectile function (IIEF): a multidimensional scale for assessment of erectile dysfunction. Urology. 1997;49(6):822-830.

11. Heidelbaugh JJ. Management of erectile dysfunction. Am Fam Physician. 2010;81(3):305-312.

12. Montorsi F, Adaikan G, Becher E, Giuliano F, Khoury $\mathrm{S}$, Lue TF, Sharlip I, et al. Summary of the recommendations on sexual dysfunctions in men. J Sex Med. 2010;7(11):3572-3588.

13. Blumentals WA, Gomez-Caminero A, Joo S, Vannappagari $\mathrm{V}$. Is erectile dysfunction predictive of peripheral vascular disease? Aging Male. 2003;6(4):217-221.

14. Ghanem HM, Salonia A, Martin-Morales A. SOP: physical examination and laboratory testing for men with erectile dysfunction. J Sex Med. 2013;10(1):108-110. 